\section{§5. Conception of Operation of In-situ Oxide Coating as Applied to V/Li Blanket}

Yeliseyeva, O., Muroga, T., Yao, Z.Y. (Univ. Tokyo), Tsisar, V. (PhysicoMechanical Institute, Ukraine)

Development of effective and reliable insulating coating is a key to the viability of $\mathrm{V} / \mathrm{Li}$ blanket concept. A promising way to mitigate the MHD pressure drop is to develop in-situ insulating coating onto inner wall of ducts. The continuous production of in-situ insulator oxide layer should be sustained by means of counter diffusion flows: oxygen from the oxygen-containing vanadium alloy and active solute admixture (Er, Ca or Y) from liquid lithium.

Regardless of the fact that feasibility of erbium oxide coating was verified previously, the dependence between structure of pre-oxidized V-alloy and formation of in-situ coating on the interface during long-term contact of alloy with the $\mathrm{Li}[\mathrm{Er}]$ melt has not been defined yet.

Here, the aim is to establish connection between effectiveness of $\mathrm{Er}_{2} \mathrm{O}_{3}$ coating at the interface and structure of $\mathrm{V}-4 \mathrm{Ti}-4 \mathrm{Cr}$ charged by oxygen during contact with liquid lithium doped by erbium and to develop conceptual model of interaction.s which are responsible for recovery of tritium and heat.

The rate of coating formation depends on both $\mathrm{O}$ and Er diffusion towards "liquid metal-solid metal" interface. It is known that solubility of $\mathrm{Er}$ in $\mathrm{Li}$ is very low: $\sim 0.15$ wt. $\%$ at $600{ }^{\circ} \mathrm{C}$. Therefore, it is reasonable to suppose that the formation and growth of $\mathrm{Er}_{2} \mathrm{O}_{3}$ layer at lower temperature is controlled by the erbium delivering from the liquid lithium to the interface largely than by oxygen diffusion from the bulk of oxidized zone. Very likely oxygen diffusion from solid metal to lithium started during the heating below the temperature when $\mathrm{Er}_{2} \mathrm{O}_{3}$ can be formed. Lack of erbium oxide at 500 and $550^{\circ} \mathrm{C}$ on the interface at the simultaneous loss of oxygen evidence this assumption. At the same temperature $\mathrm{CaO}$ coating is viable since calcium solubility in lithium is mach higher.

Even if $\mathrm{Er}_{2} \mathrm{O}_{3}$ coating appears on the interface at $600-700^{\circ} \mathrm{C}$ the oxygen consumption is the highest on the first time (20h). Processing (presentation) of coating thickness $(\mathrm{x})$ versus time $(\tau)$ of at different temperature as $\mathrm{x}^{\mathrm{n}}=\mathrm{k} \tau$ showed that at 600 and $650^{\circ} \mathrm{C}$ the coating growth nearly logarithmic law $(\mathrm{n} \sim 4)$ which is typical for slow kinetics of thin layer. At the $700^{\circ} \mathrm{C}$ the regularity is closely to parabola $(n=1.7)$ that means diffusion control of $\mathrm{Er}_{2} \mathrm{O}_{3}$ growth.

In the whole obtained kinetic data (in the range $500-700^{\circ} \mathrm{C}$ ) testifies intensification of $\mathrm{Er}+\mathrm{O} \rightarrow \mathrm{Er}_{2} \mathrm{O}_{3}$ with temperature. However with temperature the recovery process intensifies as well. That leads to destabilization of TiO net-structure and partial oxygen diffusion into non-oxidized region of V-alloy. The HV-profile after exposure at $700^{\circ} \mathrm{C}$ for $100 \mathrm{~h}$ confirms this fact. The oxygen

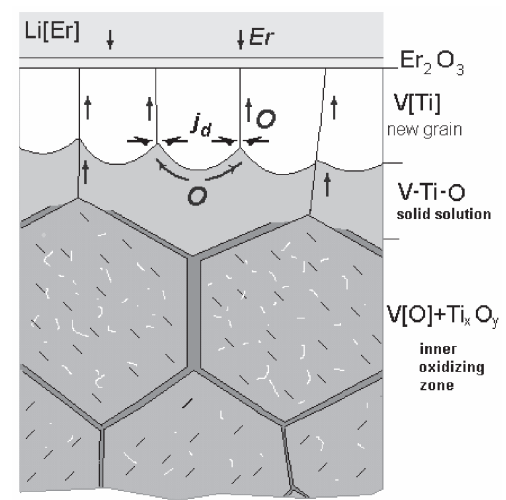

Fig. 1 Mechanism of interaction of oxygen containing V-4Ti-4Cr with $\mathrm{Li}[\mathrm{Er}]$

leakage into vanadium matrix could be a major failure of coating at long-term test.

Nevertheless the formed coating is thought to be stable enough. It can bee seen that in spite of total oxygen depletion after $300 \mathrm{~h}$ exposure at $700 \mathrm{C}$ the coating exists still on the surface of alloy. Moreover, it was shown that the coating previously formed in $\mathrm{Li}[\mathrm{Er}]$ kept his integrity in pure lithium at $700^{\circ} \mathrm{C}$ after $400 \mathrm{~h}$. The additional investigation proved that creaking revealed in a thick $(1.0-1.2 \mu \mathrm{m})$ coating occurred during cleanout of samples from lithium and therefore could be avoided in real cooling system. The crack area in the coating was recovered after re-exposure in $\mathrm{Li}[\mathrm{Er}]$ by a thin layer with high contents of erbium and oxygen. That indicated self-healing capability of coating in case of damage.

Fig.1 illustrates the mechanism of columnar structure formation in the deoxidizing zone during contact of charged V-alloy with $\mathrm{Li}[\mathrm{Er}]$. The vanadium matrix donates oxygen to lithium. First and foremost deoxidizing starts near surface region and grain boundaries. That causes dissipation of ordered $\mathrm{TiO}$ net-structure and appearance of non-equilibrium defects (dislocations, vacancies) in the V-Ti-O solid solution. Re-arrange of released defects causes the new boundaries along the oxygen flow. The new phase $\mathrm{V}[\mathrm{Ti}]$ originates near the initial interface where the oxygen content is lowermost. New grains grow in opposite direction where oxygen outflow causes dissipation of $\mathrm{TiO}$ net-structure. In fact, it is reverse phase transformation relatively to that at charging procedure.

It seems that non-equilibrium defects (dislocations, vacancies, etc) accumulated in the oxidized zone at the charging procedure act a significant role for coating viability. Since the oxygen lattice diffusion (bulk diffusion) is limited at $600-700^{\circ} \mathrm{C}$ the new diffusion paths are primary importance in delivering of oxygen from the bulk to the interface to originate and keep the integrity of $\mathrm{Er}_{2} \mathrm{O}_{3}$ coating.

Thus, due to high density of $\mathrm{TiO}$ (acting as an oxygen sources) and structure non-equilibrium defects (acting as a paths for oxygen diffusion) the oxygen concentration required for $\mathrm{Er}_{2} \mathrm{O}_{3}$ coating can be provided at the interface. Consequently, applying to in-situ oxide coatings the essence of the V-4Ti-4Cr treatment should be aimed at the creation of non-equilibrium structure contained both oxygen and defects. 